2013-02-01

Frost hardiness expression and characterisation in wheat at ear emergence

\author{
Al-Issawi, M \\ http://hdl.handle.net/10026.1/1263 \\ 10.1111/j.1439-037X.2012.00524.x \\ Journal of Agronomy and Crop Science. \\ Wiley
}

All content in PEARL is protected by copyright law. Author manuscripts are made available in accordance with publisher policies. Please cite only the published version using the details provided on the item record or document. In the absence of an open licence (e.g. Creative Commons), permissions for further reuse of content should be sought from the publisher or author. 


\title{
MISCELLANEOUS
}

\section{Frost Hardiness Expression and Characterisation in Wheat at Ear Emergence}

\author{
M. Al-Issawi ${ }^{1}$, H. Z. Rihan ${ }^{1}$, N. El-Sarkassy ${ }^{2}$ \& M. P. Fuller ${ }^{1}$ \\ 1 Faculty of Science and Technology, School of Biomedical and Biological Sciences, University of Plymouth Plymouth, UK \\ 2 Faculty of Agriculture, Zagazig University Zagazig, Egypt
}

Keywords

acclimation; anthesis; Cbf gene; frost

tolerance; supercooling; wheat

\section{Correspondence}

M. P. Fuller

Faculty of Science and Technology

School of Biomedical and Biological Sciences

University of Plymouth

Plymouth PL4 8AA, UK

Tel.: 0772226146

Fax: 01752587634

Email: mfuller@plymouth.ac.uk

Accepted May 11, 2012

doi:10.1111/j.1439-037X.2012.00524.x

\begin{abstract}
Occasionally, wheat can be exposed to overnight freezing temperatures whilst it is in the early reproductive stage and considerable frost damage can occur. In the vegetative stage, full expression of frost tolerance genes can be gained when plants are exposed to acclimation temperatures $\left(4^{\circ} \mathrm{C}\right)$. Paradoxically, wheat during flowering has limited or no ability to effectively acclimate or re-acclimate and it demonstrates frost sensitivity during this stage. Using a combined approach involving infrared thermography and molecular analysis, the causes and effects of frost-induced damage to wheat during ear emergence were investigated. It was demonstrated that frost damage only occurs to wheat ears if the temperature falls below $-5{ }^{\circ} \mathrm{C}$ but some ears, and some spikelets on frozen ears do not freeze but supercool and escape freezing. In whole plant freezing experiments, spikelets showed both complete and partial sterility upon maturation and this was linked to parallel infrared observation of detached ears showing full or partial freezing of spikelets. It was hypothesised that wherever spikelet freezing occurred the spikelet was sterile and grain production per ear was drastically reduced, and in contrary, spikelet survival was as a result of supercooling. Molecular analysis of the upregulation of $C b f 14$ showed that as ear emergence progressed the ability to induce $C b f 14$ decreased but at early stages of ear emergence $C b f 14$ was able to be induced by exposure to acclimating temperatures $\left(4^{\circ} \mathrm{C}\right)$. The hypothesis that the lack of the ear to acclimate is because of the incapability to induce the CBF transcription factor was only partially upheld in this investigation. Further work is needed to elucidate more precisely the molecular incompetency for the acclimation of wheat during ear emergence.
\end{abstract}

\section{Introduction}

In Australia particularly and in other regions of the world such as subtropical zones, the Mediterranean and continental climatic zones wheat and other temperate grain crops can be exposed to freezing during or after ear emergence and huge loss of yield can occur (Fuller et al. 2007, 2009, Chen et al. 2009, Thakur et al. 2010). During these late developmental stages, both male and female reproductive organs appear to be frost sensitive and frost damage reduces grain set and thereby yield (Thakur et al. 2010). In Iraq, during the crop season 1979/1980, frosty weather prevailed in the northern parts (Nineveh governorate, which accounts for $50 \%$ and $25 \%$ of the country's wheat and barley area, respectively) when cereals crops were in the late flowering to early dough stage, and average frost damage recorded was $50 \%$. Grain yield was lost owing to damage to whole or parts of ears when they failed to develop further and took on a bleached appearance (Tarik 1981). In southern Queensland, Australia, frost damage losses to wheat crops during flowering are estimated to cost the Australian grain industry $\mathrm{A} \$ 100$ million per year (Tshewang et al. 2010). In China, Zhong et al. (2008) reported that the probability of frost damage to wheat was nearly $40 \%$ in the 1970 s, rising about $50 \%$ in 1980 s and $78 \%$ in 1990s and damage occured when low temperatures coincided with sensitive late plant growth stages. Whilst crop damage at this time can be caused by decreased 
photosynthesis, leaf death or stem damage, it is apparent that ear or spikelet death is responsible for most of the recorded losses (Zhong et al. 2008).

Wheat in the vegetative stage is tolerant of freezing and this tolerance is determined by a complex interaction between physical and biochemical factors that are dependent on both genotype and environmental stimuli leading to acclimation induced by low non-freezing temperatures (Thomashow et al. 2001). Cold acclimation is regulated by the $\mathrm{Cbf}$ (C-repeat Binding Factor) regulon, which been discovered through the investigations of cold-regulated genes in Arabidopsis (Fowler et al. 2007). Cbf upregulation is considered to be the first indicator of whether acclimation is being induced by exposure to low temperature (Zarka et al. 2003, Thomashow 2010). The induction of Cbf genes starts within $15 \mathrm{~min}$ of exposure to low temperature (around $4{ }^{\circ} \mathrm{C}$ ) and triggers a cascade of upregulation of target cold genes (e.g. Cor15) after about 2-3 h (Thomashow 2010). Full expression of frost tolerance genes occurs in the vegetative stage and wheat plants in the vegetative stage can re-acclimate after exposure to warm temperature and de-acclimation (Paulsen and Heyne 1983, Cromey et al. 1998). In contrast in the reproductive stage, wheat has been reported to have limited or no ability to re-acclimate (Mahfoozi et al. 2001) and Cbf and Cor gene expression is assumed to be reduced after vegetative/reproductive transition (Fowler et al. 1999, Mahfoozi et al. 2001, Limin and Fowler 2006). There is very little detailed information in the literature on the frost characteristics of wheat during ear emergence but supercooling ability and thereby frost avoidance has been observed both in frost tests and in the field (Fuller et al. 2007, 2009a). It can be hypothesised that the frost damage that occurs during late development stages in wheat is owing to the failure of the upregulation of $C b f$ following exposure to normally inductive low temperature but such studies have not been reported to date. The work reported here is a result of an investigation of the expression of $\mathrm{Cbf} 14$, which showed the highest transcript levels upon transfer wheat plants to low temperatures (Vágújfalvi et al. 2005) during and after flowering and the characterisation of the ice nucleation behaviour in wheat ears using infrared thermography.

\section{Materials and Methods}

\section{Plant materials}

Three experiments were carried out to characterise and analyse the frost hardiness expression of wheat during flowering. A European winter cultivar (cv. Claire) with moderate un-acclimated frost tolerance (LT50 of approximately $-5{ }^{\circ} \mathrm{C}$ ) and a reasonable capacity for acclimation (LT50 of approximately $-9^{\circ} \mathrm{C}$ ) (Fuller et al. 2007) was used.
All experiments were carried out at Plymouth University, United Kingdom during 2008, 2009 and 2010. In the first experiment, detached ears were used in a frost chamber, which enabled the monitoring of individual ears and a controlled thermal regime, which is impossible in the field. The other experiments were non-destructive and used whole plants that were followed through to yield. Plants were either collected from a field crop or grown in large square containers $(30 \times 30 \mathrm{~cm} \times 25 \mathrm{~cm}$ deep $)$ buried into the ground in a raised bed. All plants were grown at a population density equivalent to 200 plants per $\mathrm{m}^{-2}$.

\section{Experiment 1 - frost resistance of ears of winter wheat}

Ears of wheat were collected from the field on two occasions at two growth stages; A - Ear 7/8th emerged (Z59) and C anthesis (Z65) (Zadoks et al. 1974) in the early morning when all plant tissues were fully turgid during early June 2008 when the temperature was higher than the cold acclimation threshold (circa $19{ }^{\circ} \mathrm{C}$ ) according to weather data recorded at the Plymouth University weather station. The cut stems were immediately sealed with Vaseline (petroleum jelly) and placed into an insulated chilled plastic box containing ice packs and transferred within $1 \mathrm{~h}$ to a refrigerator at $4{ }^{\circ} \mathrm{C}$ in the dark and stored until frost tested in the afternoon of the same day. Thirty ears were arranged onto a tray (Plate 1a) and were frozen in a dry condition to $0,-2,-4$, -6 and $-8{ }^{\circ} \mathrm{C}$ with a $2 \mathrm{~h}$ hold at each temperature in an M533 Sanyo programmable cabinet. A further 10 ears were maintained as controls and kept in the refrigerator at $4{ }^{\circ} \mathrm{C}$. During freezing, the tray of ears was observed using an infrared thermal imaging camera (Inframetrics 760) to visualise the spontaneous ice nucleation and subsequent freezing/ supercooling patterns. Images were recorded in real time on videotape and later analysed using Thermagram ${ }^{\mathrm{TM}}$ software (Thermotechniks Systems Ltd, Cambridge, UK) which enabled temperature tracking of the background temperature (confirmed visually using a cross-hair point see Plate 1) and individual spikelets on ears. Ice nucleation was detected visually by the sudden colour change of a point on a spikelet from blue to light blue/white which then quickly spread. Subsequently, freezing was confirmed by subtracting the background temperature from the spikelet temperature (delta ${ }^{\circ} \mathrm{C}$ ) to give an exotherm trace (Fig. 1). The experiment was repeated three times. Data derived from this experiment included the percentage of ears that froze/ supercooled, the temperature of freezing and the level of frost damage as estimated by a relative electrical conductivity (REC) (Aronsson 1980, Levitt 1980, Fuller et al. 1989).

Experiment 2 - non-destructive estimate of damage to ears of wheat caused by low temperature and freezing

Thirty-six pots of wheat were allocated at random into three groups in the summer of 2009 when the environmental 

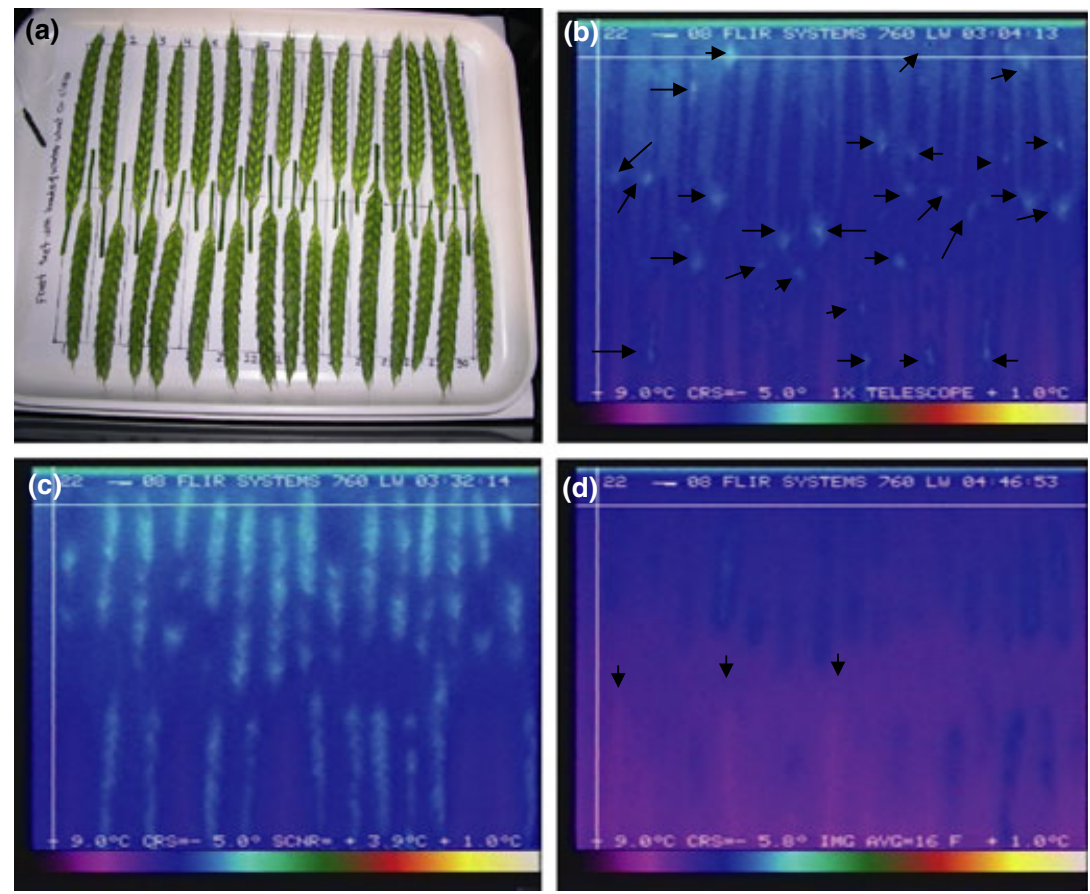

Plate 1 (a) Layout of 30 wheat ears (replicate 1 of 3 ) frozen to $-6^{\circ} \mathrm{C}$. (b) Infrared image of the same ears 15 minutes after reaching $-5{ }^{\circ} \mathrm{C}$ showing exothermic ice nucleation events (lighter patches - arrowed). Crosshair (CRS) shows background temperature and bottom scale shows a $10{ }^{\circ} \mathrm{C}$ span from +1 to $-9{ }^{\circ} \mathrm{C}$. (c) Infrared image 30 minutes later than B showing ears with the exothermic events spreading widely throughout ears but with some spikelets not showing exotherms. (d) Infrared image 1 hour 15 minutes later than $\mathrm{C}$ showing some ears still showing exothermic events but 3 ears (arrowed, 10\% of sample) which have supercooled.

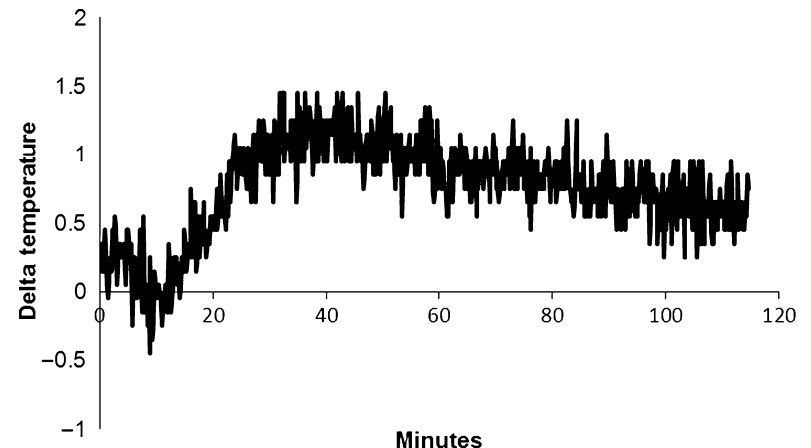

Fig. 1 Typical spikelet exotherm trace derived from infrared thermography using Thermagram ${ }^{\mathrm{TM}}$ software. (Delta Temperature $=$ spikelet temperature - background temperature, ice nucleation began at $-5^{\circ} \mathrm{C}$ ).

condition was favourable for growth. The groups were allocated to represent the following three growth stages (12 pots per Zadoks GS):

A: (Z51-Z60) from $10 \%$ of spikes visible (ear peep) to whole spike visible,

B: (Z61-Z69) from early $20 \%$ spike with anthers to late

$90 \%$ spikes with anthers

C: (Z70.2-Z79) from Kernels middle spike extended $20 \%$ to: very late milk, half solid in milk.

When the majority of plants reached the allocated growth stage, the pots were lifted from the raised bed and re-allocated to one of four treatments (T1-T4) (three pots each)
T1: kept in the field (control - non-acclimated and non-frozen).

T2: transferred directly to the frost chamber (non-acclimated) and exposed to the following freezing regime.

$1{ }^{\circ} \mathrm{C}$ for $1 \mathrm{~h}, 0{ }^{\circ} \mathrm{C}$ for $2 \mathrm{~h},-2{ }^{\circ} \mathrm{C}$ for $2 \mathrm{~h},-4{ }^{\circ} \mathrm{C}$ for $2 \mathrm{~h},-6{ }^{\circ} \mathrm{C}$ for $2 \mathrm{~h}$ and then defrosted at $1{ }^{\circ} \mathrm{C}$ for $1 \mathrm{~h}$.

T3: transferred to the acclimation chamber at $4{ }^{\circ} \mathrm{C}$ and $8 \mathrm{~h}$ light $\left(177 \mu \mathrm{mol} \mathrm{m} \mathrm{m}^{-2} \mathrm{~s}^{-1}\right)$ for 14 days and then returned back to the field (acclimated but not frozen).

T4: transferred to the acclimation chamber and then frost tested in the frost chamber (acclimated and frozen) using the same freezing regime which applied to T2.

All pots were then returned to the raised bed, reburied and left to grow on until maturity. Ears were then collected and for each individual ear, spikelets were counted, the ear threshed and the number of grains counted. The mean number of grains per spikelet was then calculated to get the fertility ratio or spikelet fertility (Scott and Langer 1977).

Experiment 3-molecular analysis for Cbf expression of wheat during ear emergence

The expression of Cbf14 because of acclimation was investigated in both young vegetative plants and in field grown plants during ear emergence. For the vegetative assessment, seeds were sown in seed trays and plants were raised to the 4-5 leaf stage (ZGS14 - 15). Trays were randomly divided 
into two groups: unacclimated at $20^{\circ} \mathrm{C}$ and acclimated at $4{ }^{\circ} \mathrm{C}$ and trays were transferred to the respective controlled environment rooms. Vegetative samples (leaves and pseudostem) were then collected after $0,8,24 \mathrm{~h}$ and 14 days and immediately transferred to $-80{ }^{\circ} \mathrm{C}$ for subsequent mRNA extraction. For the ear emergence assessment, the experimental set-up described in Experiment 2 was reestablished in 2009/2010 and ear and flag leaf samples for molecular analysis were collected from plants grown from two of the growth stages (GSA and GSB) exposed to either 20 (unacclimated) or $4{ }^{\circ} \mathrm{C}$ (acclimated). Pots at each of the ear emergence growth stages were lifted from the raised bed and transferred to the respective controlled environments. Samples were then collected after 0, 8, $24 \mathrm{~h}$ and 14 days and immediately transferred to $-80{ }^{\circ} \mathrm{C}$ for subsequent mRNA extraction.

\section{Molecular analysis}

Frozen ears/leaves (100 mg \pm 10$)$ were ground in liquid nitrogen with a mortar and pestle. The total RNA was isolated using Sigma reagents (spectrum plant total RNA kit, Cat \# STRN50; Sigma-Aldrich (Sigma-Aldrich, Dorset, UK)) according to manufacturer's instructions. Extracted RNA was quantified with a Nanodrop 1000 to estimate concentration and then stored at $-80{ }^{\circ} \mathrm{C}$. The first strand cDNA was obtained by using M-MLV Reverse Transcriptase (M1302: Sigma-Aldrich) in $20 \mu \mathrm{l}$ volume on RNA isolated from either leaves or ears.

Forward and reverse PCR primers were designed for the Cbf14 gene that has previously been shown to give the highest transcript levels within $15 \mathrm{~min}$ (Vagujfalvi et al. 2005). Primers for the gene were designed with wheat gene sequences obtained from Blast software and forward primer Cbf14-Int-F 5'-CCGTTCAGCACCGCCAAGGC-3' and reverse primer Cbf14-Int-R 5'-CCATGCCGCCAAACCAGTGC-3' obtained from Eurofins MWG. cDNA was used as a template for the PCR detection system. The master mix consisted of $1 \mu \mathrm{l}$ Red-Taq, $2.5 \mu \mathrm{l}$ Red-Taq buffer, and $0.5 \mu \mathrm{l}$ forward and reverse primers, $0.5 \mu \mathrm{l}$ dNTPs and $18 \mu \mathrm{l}$ M. $\mathrm{H}_{2} \mathrm{O}$ and was added to $2 \mu \mathrm{l} \mathrm{cDNA}$ to make a final volume of $25 \mu \mathrm{l}$. The reaction mixture for each sample was run under the following thermal cycle: initial denaturation at $94{ }^{\circ} \mathrm{C}$ for $2 \mathrm{~min}$ once followed by 40 cycles of (denaturation at $94{ }^{\circ} \mathrm{C}$ for $30 \mathrm{~s}$, annealing at $60{ }^{\circ} \mathrm{C}$ for $30 \mathrm{~s}$, extension at $72{ }^{\circ} \mathrm{C}$ for $30 \mathrm{~s}$ ) and a final extension at $72{ }^{\circ} \mathrm{C}$ for $5 \mathrm{~min}$ and then held at $4{ }^{\circ} \mathrm{C}$. A gel of $2 \%$ agarose was prepared and SYBR safe dye was used to stain the DNA. The gel was run at $90 \mathrm{~V}$ until the bromophenol blue running dye front was about 3/4 through the gel (approximately $1 \mathrm{~h}$ ). The tray with the agarose gel was carefully removed and examined under UV light in a transilluminator and later analysed using gel imaging software.

\section{Results}

\section{Experiment 1 - frost resistance of ears of winter wheat}

Infrared thermography revealed that the actual temperature of the ears lagged behind the set point of the freezing chamber by approximately $1.0^{\circ} \mathrm{C}$. Ice nucleation did not occur during the 2 hour hold times at set points of -2 nor at $-4{ }^{\circ} \mathrm{C}$. Ice nucleation began after $15 \mathrm{~min}$ exposure to the $-6{ }^{\circ} \mathrm{C}$ set point when ears fell to a temperature of $-5.0^{\circ} \mathrm{C}$ and nucleation occurred at random positions on the ear (Plate 1). The intensity of an exotherm was seen to give a bright light blue image and individual spikelets on an ear were clearly visible as freezing spread between spikelets until the whole ear was frozen (Plate 1). Most ears were fully frozen $45-60 \mathrm{~min}$ after ice nucleation and by 120 min the heat of crystallisation had begun to dissipate and the ears started to become isothermal and the colour returned to the darker blue/purple of the background. It was noticeable that $10-15 \%$ of ears in each replicate did not show any ice nucleation and had supercooled (e.g. Plate 1D shows 3 supercooled ears $(10 \%$ of those tested)).

The observation by infrared thermography which showed that ears did not freeze at the -2 or $-4{ }^{\circ} \mathrm{C}$ treatments and only began freezing when the temperature fell below $-5{ }^{\circ} \mathrm{C}$ was supported by the REC \%'s which showed that no damage occurred at -2 or $-4{ }^{\circ} \mathrm{C}$ (Fig. 2). At -6 and $-8{ }^{\circ} \mathrm{C}$, only those ears that were identified to exotherm and freeze showed an increase in REC \%, indicating frost damage, whereas those that had supercooled had REC \%'s which were not significantly differ from the unfrozen controls. This pattern was similar for both growth stages studied $(\mathrm{a}, \mathrm{b})$.

Experiment 2 - non-destructive estimate damage to ears of wheat caused by low temperature and freezing

The non-acclimated/unfrozen control (T1) showed a fertility ratio of around 2.5 grains per spikelet equating to approximately 50 grains per ear, which is typical for European winter wheat (Scott and Langer 1977) (Fig. 3). Exposure to acclimation $\left(4^{\circ} \mathrm{C}\right.$ and $8 \mathrm{~h}$ light) for 14 days during flowering (T3) had a slight negative on fertility ratio, which was most noticeable at GSB when the plants were closest to anthesis, and the mean ambient temperature prior to acclimation was around $13{ }^{\circ} \mathrm{C}$.

When the plants were exposed to subzero treatment (T2 and T4), then fertility was drastically reduced indicating a big effect of freezing. However, fertility was not reduced to zero and observations during threshing showed that ears contained mostly spikelets with zero grains but with a few fully fertile spikelets (Fig. 3; Plate 2). These observations 

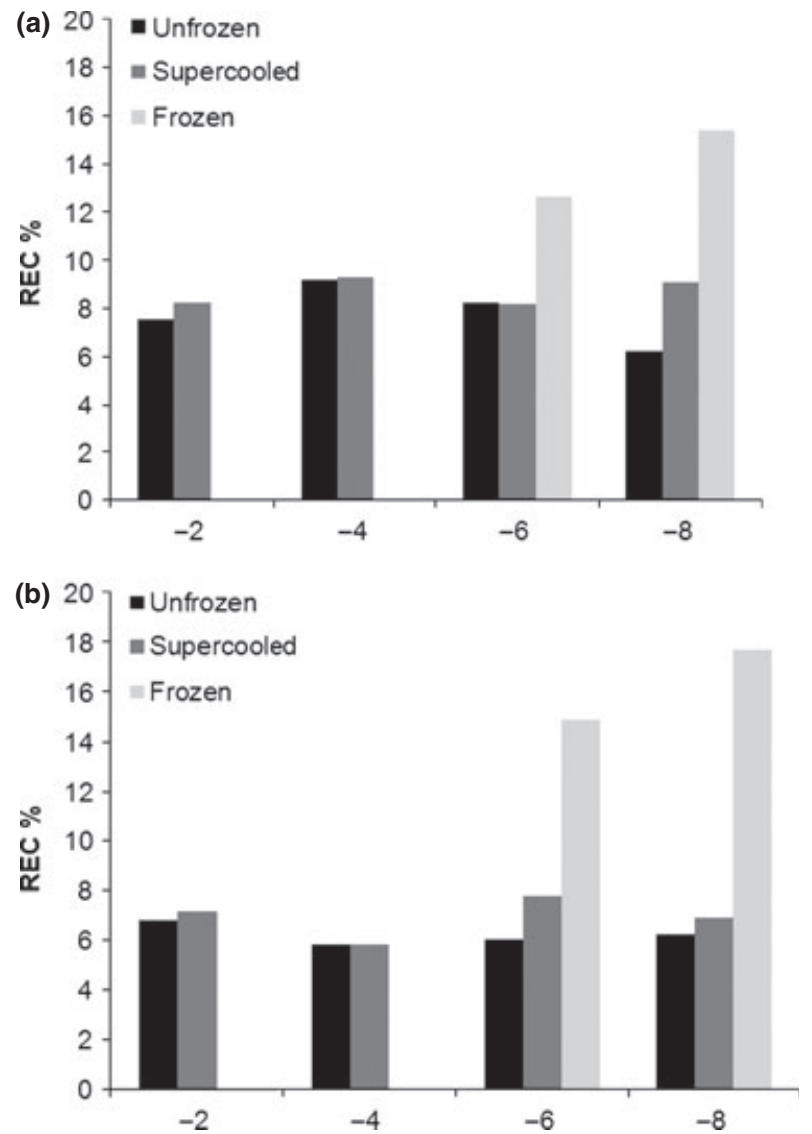

Fig. 2 Relative electrical conductivity (REC \%) of groups of ears of winter wheat at two growth stages (a: Zadoks 59, b: Zadoks 69); unfrozen (control); supercooled and frozen.

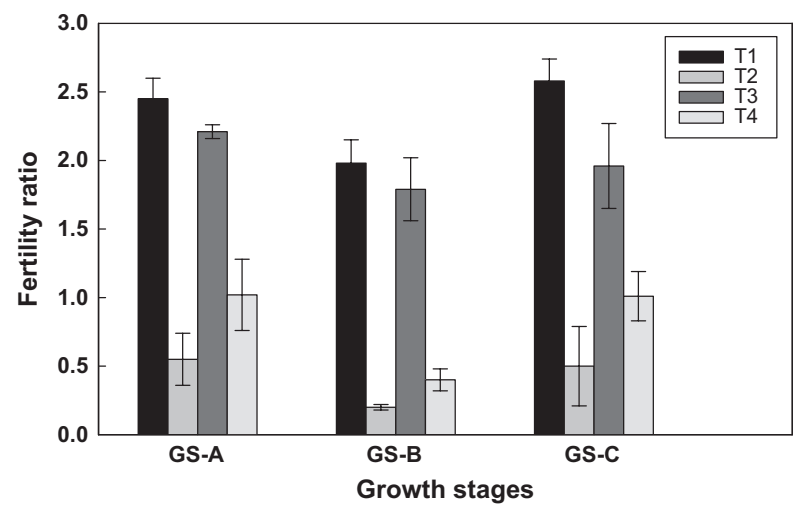

Fig. 3 The effect of temperature on fertility ratio (grains/spikelet) of wheat cv. Claire at three growth stages during ear emergence (see text for detail) exposed to four temperature treatments (T1 control; T2 frozen $\left(-6^{\circ} \mathrm{C}\right) ; \mathrm{T} 3$ acclimated but not frozen; T4 acclimated and frozen $\left(-6{ }^{\circ} \mathrm{C}\right)$ ). Error bars are \pm S.E. (sample sizes vary from $n=29-88$ ).

suggest that the frost damage was not distributed evenly across the ear and that some spikelets appeared to escape frost damage completely.
The results showed that the acclimation process only had a small positive effect within each growth stage with the acclimated and frozen treatment (T4) showing slightly higher fertility ratio than their non-acclimated and frozen equivalents (T2).

\section{Experiment $3-C b f$ expression in wheat during ear emergence}

Cbf14 expression was clearly increased during acclimation of vegetative plants (Fig. 4) and was highly expressed after 8 and $24 \mathrm{~h}$ and then decreased but was still detectable after 14 days acclimation an expression pattern reported extensively in the literature. There was no Cbf14 expression in non-acclimated plants.

After reproductive transition the results clearly showed that $C b f 14$ was not expressed in unacclimated plants but did show some expression in both flag leaves and ears especially at the earlier growth stage A (Z51-Z59) but with much less expression at growth stage B (Z60-Z69). The highest expression was found after $8 \mathrm{~h}$ exposure to LT in growth stage $A$ and then decreased after $24 \mathrm{~h}$. In growth stage B, the Cbf14 seemed to be only expressed after $24 \mathrm{~h}$ of acclimation and then disappeared by 14 days (Fig. 5).

\section{Discussion}

Wheat plants are inherently tolerant to a degree of exposure to subzero temperature and Fuller et al. (2007) showed that unacclimated wheat $\mathrm{cv}$. Claire tolerated down to $-5{ }^{\circ} \mathrm{C}$ without freezing damage and this tolerance can be further improved in vegetative plants by acclimation. However, as soon as the vernalisation requirements (cold induction days to flowering) are fulfilled and reproductive transition occurs, wheat becomes susceptible to the loss of cold hardiness (de-acclimation) as temperatures rise and plants appear to lose their capability to re-acclimate (Fowler et al. 1996, Mahfoozi et al. 2001, Prasil et al. 2004, Fuller et al. 2007). Although wheat varieties differ in their ability to survive low temperature in the vegetative form, all varieties appear to become relatively susceptible to frost after vegetative/reproductive transition and after full de-acclimation at the end of the winter. The results here also confirmed those of Fuller et al. $(2007,2009)$ in that not all ears that are exposed to subzero temperatures actually freeze but some are able to supercool and remain undamaged by the freezing temperatures. The infrared observations of wheat ears during freezing also showed that of the ears that do freeze not all freeze at the same time and freezing does not always spread to all of the spikelets on an ear. This finding helps to explain the observations of nondestructive tests and those reported from field observations, which show extensive but not complete spikelet 

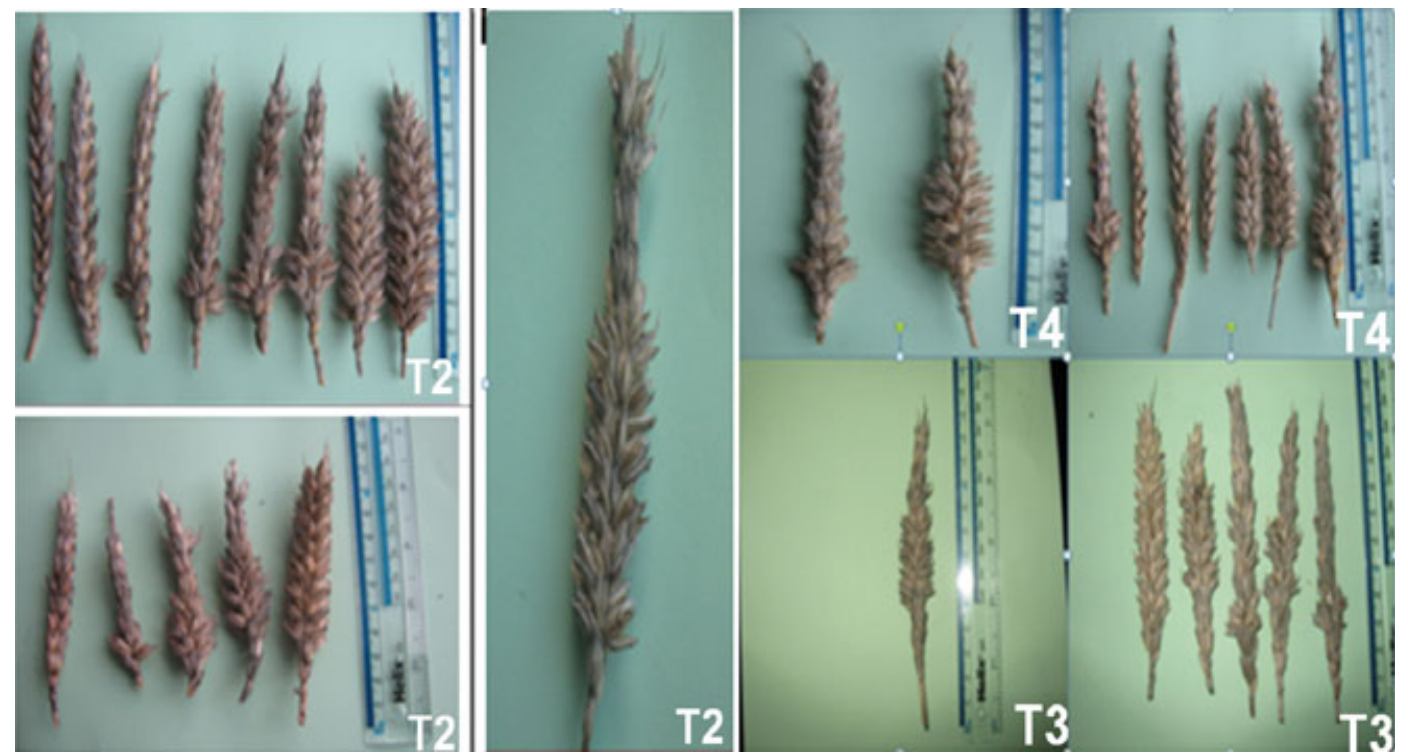

Plate 2 Plate spikes of winter wheat at maturity following exposure to various temperature treatments showing fertile (with grains) and sterile (no grains) spikelets.

sterility caused by freezing exposure. Initial ice nucleation of an ear occurred at various locations and there was no distinct pattern to this. It is thought that this is not atypical because a similar finding has been observed by infrared imaging during freezing in the field (Fredericks pers.com). The reason for the initial random ice nucleation is not known but dew formation may provide possible ice nucleation sites and it is possible that overnight a spikelet may guttate and the droplet of water may form a site for ice nucleation from which ice spreads back into the ear itself. In the field in Australia where ear frost damage is acute, there is relatively little incidence of dew formation during ear emergence because the atmosphere has a very low $\mathrm{RH} \%$ and in such situations external ice nucleation may be less likely and supercooling more likely. Infrared thermography showed that the spread of ice along ears from the site of initial nucleation often proceeded in an erratic manner suggesting that there are barriers or restrictions to ice travel within the ear and it is likely that these are at the nodal regions at the point of attachment of the spikelets to the rachis, this was also noted by Pearce (2001). Ice may well not spread into some spikelets at all and these therefore supercool and are undamaged. Also independent ice nucleation events may appear at secondary locations in the ear. Notwithstanding the irregular pattern of ice nucleation and ice spread, it was evident that only ears that had actually frozen showed frost damage as measured by REC \% and supercooled ears showed no frost damage. The REC \%'s measured were, however, low (15-20\%) compared with those recorded in many other frost hardiness experiments where significant cellular frost damage is indicated by REC \%'s of 75-90 \% (Fuller et al. 1989). This suggests that in the ear freezing experiments the actual cell damage caused by freezing was not that extensive. However, the results of the non-destructive experiments showed that in terms of spikelet fertility there was frequently total loss of fertility at these temperatures. Fuller et al. (2007) also observed this and it is proposed that cellular frost damage does not need to be extensive but if it affects critical reproductive organs then the net effect is sterility, which is catastrophic for yield. It appears therefore that the likelihood of damage to ears of wheat from a transient frost will
Fig. 4 CBF14 expression during vegetative stage after $0,8,24 \mathrm{~h}$ and 14 days exposing to LT.

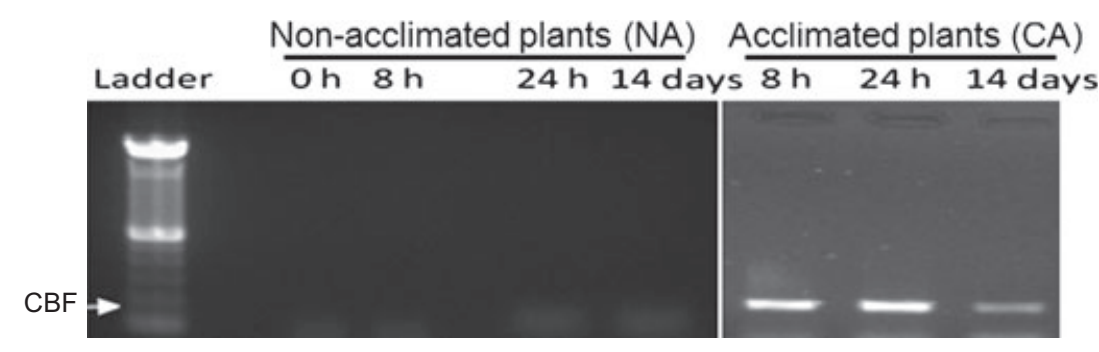




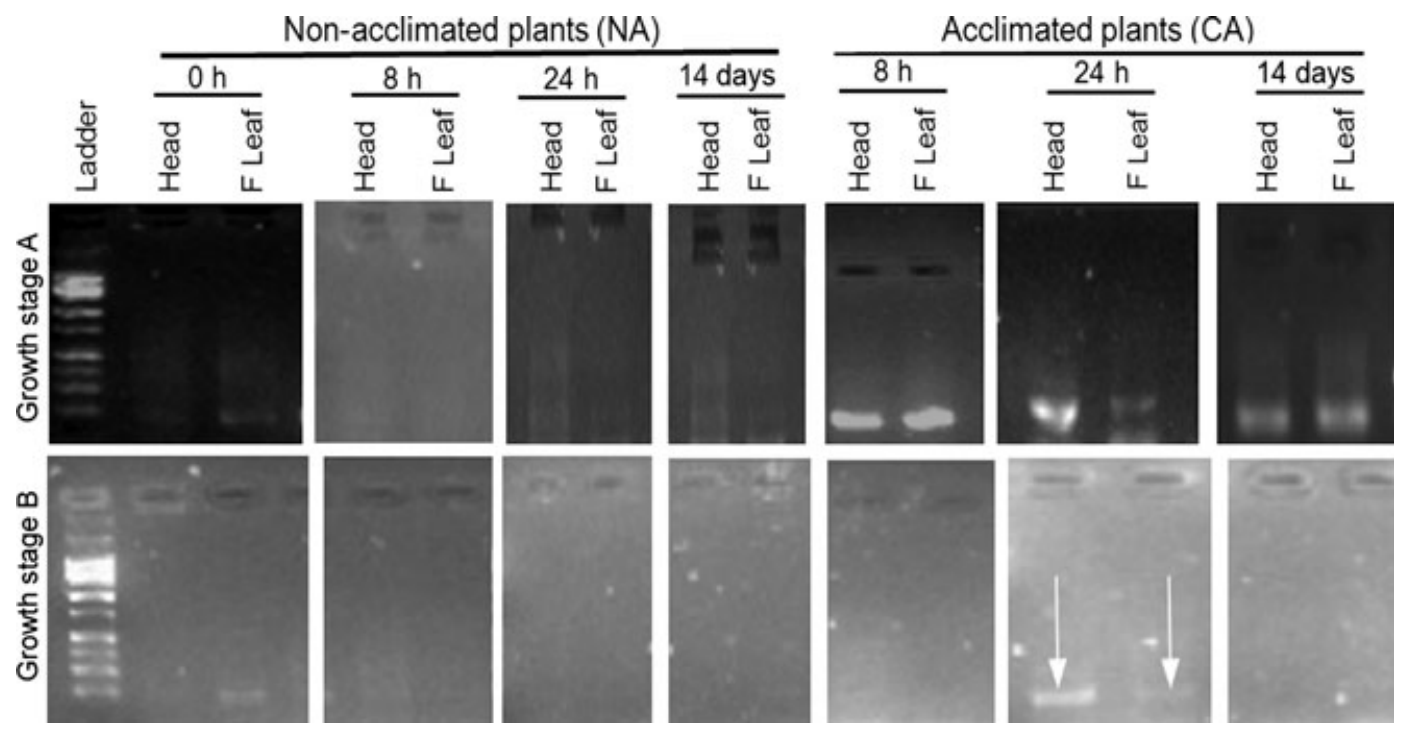

Fig. 5 CBF14 expression in winter wheat at two growth stages $(a, b)$ during ear emergence in acclimated and non-acclimated plants (NA \& a) after $0,8,24 \mathrm{~h}$ and 14 days.

depend on the depth of freezing and whether the temperature falls below $-5{ }^{\circ} \mathrm{C}$ when the risk of ice nucleation increases significantly. Also the duration of freezing below $-5{ }^{\circ} \mathrm{C}$ is important as it will increase the likelihood of ice nucleation events occurring and the subsequent spread of ice throughout the ear. It is acknowledged that the two parts of this study are tied together rather speculatively because one of the limitations of using REC \%'s for detecting frost damage is that it is a destructive technique and it is not possible to follow individual ears temporally to seed set. Extensive use of infrared thermography may be able to overcome this speculation in future experimentation.

From the findings of this study, supercooling of wheat ears appears to be a realistic mechanism for wheat to escape damage from transient frosts. At present, nothing is known as to whether or not there is any genetic variation associated with supercooling ability or whether it is a totally random stochastic event. It is not therefore known whether plant breeding could select for a propensity to supercool in wheat. However, the manipulation of supercooling presents itself as a potential target for abiotic frost protection of wheat during ear emergence. This has been demonstrated for high-value fruit and vegetable crops (Wisniewski et al. 2002, Fuller et al. 2003, Gusta et al. 2009) but the lower value of wheat coupled with the extensive acreages over which it is grown means that solutions need to be inexpensive and easily applied.

Mahfoozi et al. (2001) and Fowler et al. (2007) have suggested that once the vernalisation requirement has been fulfilled in wheat, the expression of genes for cold acclimation are switched off, claiming that genes for vernalisation are the master switch for cold acclimation genes and wheat would only be able to resist frost to its constitutive frost resistance level, which appears to be around $-5^{\circ} \mathrm{C}$. Fuller et al. (2007, 2009a,b) also proposed that acclimation cannot be triggered in wheat plants at the ear emergence stage and the plant is insensitive to acclimation temperatures. This is largely upheld in this study although there is limited evidence of acclimation in flag leaves but not in ears themselves (Fig. 3). The molecular analysis (Cbf14 upregulation) partially upholds this hypothesis. As ear emergence progressed, the ability to upregulate Cbf14 declined but at an early stage of ear emergence $C b f 14$ could still be upregulated. As the early ear emergence stage is several months after vernalisation is fulfilled, it is unlikely that vernalisation provides the 'Master switch' for acclimation gene regulation via $C b f$ control. However, despite the cold-induced upregulation of Cbf14 at early ear emergence, acclimation did not occur suggesting that the control of frost resistance by vernalisation is either downstream of the $C b f$ transcription factor or on a different path to that in which Cbf14 operates. The most highly induced genes during acclimation are COR, KIN, RD, LTI and ERD (Thomashow 1998) and some of these genes act directly to stimulate the production of cryoprotective polypeptides (COR15a), but generally the proteins encoded by these genes are extremely hydrophilic, and they could be members of the dehydrins (Close 1997) or LEA (Wise and Tunnacliffe 2004) protein families (Fowler et al. 2007). It is possible that despite Cbf induction its regulon is not induced. Further work is still necessary to determine the exact point of breakdown of gene upregulation for acclimation during ear emergence in wheat. 


\section{Conclusion}

Wheat was unable to cold acclimate effectively during ear emergence but some ears can supercool and escape freezing. Frozen ears did not always freeze uniformly and some spikelets on a frozen ear could escape freezing and damage. The irregular spread of ice through the spikes indicated that ice spread is a complex physical process, which can be slowed down or temporarily stopped at complex nodal junctions in the rachis. Cbf14 can still be upregulated by acclimating temperatures early stages of ear emergences but less so at later stages. The lack of ability of ears to acclimate therefore appears to be a combination of either a lack of inducible $C b f$ and/or downstream $C b f$ regulon induction.

\section{References}

Aronsson, A., 1980: Frost hardiness in Scots pine (Pinus silvestris L.). II. Hardiness during winter and spring in young trees of different mineral nutrient status. Studia forestalia Suecica (0039-3150) 155, 1-27.

Chen, A., L. Gusta, A. Brûlé-Babel, R. Leach, U. Baumann, G. Fincher, and N. Collins, 2009: Varietal and chromosome $2 \mathrm{H}$ locus-specific frost tolerance in reproductive tissues of barley (Hordeum vulgare L.) detected using a frost simulation chamber. Theor. Appl. Genet. 119, 685-694.

Close, T. J., 1997: Dehydrins: a commonality in the response of plants to dehydration and low temperature. Physiol. Plant. 100, 291-296.

Cromey, M. G., D. S. C. Wright, and H. J. Boddington, 1998: Effects of frost during grain filling on wheat yield and grain structure. New Zeal. J. Crop Hort. Sci. 26, 279-290.

Fowler, D. B., A. E. Limin, S.-Y. Wang, and R. W. Ward, 1996: Relationship between low-temperature tolerance and vernalization response in wheat and rye. Can. J. Plant Sci. 76, 37-42.

Fowler, D. B., A. E. Limin, and J. T. Ritchie, 1999: Low-temperature tolerance in cereals: model and genetic interpretation. Crop Sci. 39, 626-633.

Fowler, S., D. Cook, and M. F. Thomashow, 2007: The CBF Cold-response Pathway. Blackwell Publishing Ltd, Oxford, UK.

Fuller, M. P., B. W. W. Grout, and C. R. Tapsell, 1989: The pattern of frost-hardening of leaves of winter Culiflower (Brassica oleracea var. botryits c.v. Caluse 30). An. Appl. Biol. 115, 161170.

Fuller, M. P., F. Hamed, M. Wisniewski, and D. M. Glenn, 2003: Protection of crops from frost using hydroponic particle film and an acrylic polymer. An. Appl. Biol. 143, 93-97.

Fuller, M. P., A. M. Fuller, S. Kaniouras, J. Christophers, and T. Fredericks, 2007: The freezing characteristics of wheat at ear emergence. Eur. J. Agron. 26, 435-441.

Fuller, M. P., J. Christopher, and T. Fredericks, 2009: Low temperature damage to wheat in head: matching perceptions to reality. In: L. V. Gusta, M. E. Wisniewski and K. K. Tanino, eds. Plant Cold Hardiness: From the Laboratory to the Field, pp. 12-18. CABI International, Cambridge, Maddison, WI, USA.

Gusta, L., M. Wisniewski, and K. K. Tanino, 2009: Plant Cold Hardiness. CABI International, Wallingrod, UK.

Levitt, J., 1980: Response of Plant to Environmental Stresses, 2nd edn. Academic Press, New York, NY.

Limin, A., and D. Fowler, 2006: Low-temperature tolerance and genetic potential in wheat (Triticum aestivum $\mathrm{L}$.): response to photoperiod, vernalization, and plant development. Planta 224, 360-366.

Mahfoozi, S., A. E. Limin, and D. B. Fowler, 2001: Influence of vernalization and photoperiod responses on cold hardiness in winter cereals. Crop Sci. 41, 1006-1011.

Paulsen, G. M., and E. G. Heyne, 1983: Grain production of winter wheat after spring freeze injury. Agronomy Journal 75, 705-707.

Pearce, R. S., 2001: Plant freezing and damage. Ann. Bot. 87, 417 -424 .

Prasil, I. T., P. Prasilova, and K. Pankova, 2004: Relationships among vernalization, shoot apex development and frost tolerance in wheat. Ann. Bot. 94, 413-414.

Scott, W. R., and R. H. M. Langer, 1977: A comparison of the pattern of grain set in 'Aotea' and 'Karamu' wheat. New Zeal. J. Agr. Res. 20, 357-361.

Tarik, A. T. 1981: Wheat information service No. 53. http:// www.shigen.nig.ac.jp/wheat/wis/No53/53.html [last accessed 01 May 2012].

Thakur, P., S. Kumar, J. A. Malik, J. D. Berger, and H. Nayyar, 2010: Cold stress effects on reproductive development in grain crops: an overview. Environ. Exp. Bot. 67, 429-443.

Thomashow, M. F., 1998: Role of cold-responsive genes in plant freezing tolerance. Plant Physiol. 118, 1-8.

Thomashow, M. F., 2010: Molecular basis of plant cold acclimation: insights gained from studying the CBF cold response pathway. Plant Physiol. 154, 571-577.

Thomashow, M. F., S. J. Gilmour, E. J. Stockinger, K. R. JagloOttosen, and D. G. Zarka, 2001: Role of the Arabidopsis CBF transcriptional activators in cold acclimation. Physiol. Plant. 112, 171-175.

Tshewang, S., C. Birchall, and R. Jessop, 2010: Evaluation of the frost tolerance of triticale varieties and other winter cereals at flowering, Australian Agronomy Conference, Australian Agronomy Conference, Australia.

Vagujfalvi, A., A. Aprile, A. Miller, J. Dubcovsky, G. Delugu, G. Galiba, and L. Cattivelli, 2005: The expression of several Cbf genes at the Fr-A2 locus is linked to frost resistance in wheat. Molecular genetics and genomics: MGG 274, 506514.

Vágújfalvi, A., A. Aprile, A. Miller, J. Dubcovsky, G. Delugu, G. Galiba, and L. Cattivelli, 2005: The expression of several Cbf genes at the Fr-A2 locus is linked to frost resistance in wheat. Mol. Genet. Genomics 274, 506-514.

Wise, M. J., and A. Tunnacliffe, 2004: POPP the question: what do LEA proteins do? Trends Plant Sci. 9, 13-17. 
Wisniewski, M., D. M. Glenn, and M. P. Fuller, 2002: The use of hydroponic particle films as a barrier to extrinsic ice nucleation in Plants. J. Am. Soc. Hortic. Sci. 127, 358-364.

Zarka, D. G., J. T. Vogel, D. Cook, and M. F. Thomashow, 2003: Cold induction of Arabidopsis CBF genes involves multiple ICE (inducer of CBF expression) promoter elements and a cold-regulatory circuit that is desensitized by low temperature. Plant Physiol. 133, 910-918.
Zadoks, J. C., T. T. Chang, and C. F. Konzak, 1974: A decimal code for growth stages of cereals. Weed Res. 14, 415-421.

Zhong, X., X. Mei, Y. Li, H. Yoshida, P. Zhao, X. Wang, L. Han, X. Hu, S. Huang, J. Huang, and Z. Sun, 2008: Changes in frost resistance of wheat young ears with development during jointing stage. J. Agron. Crop Sci. 194, 343-349. 